\title{
Pengembangan Buku Ajar Fisika Dasar Berbasis Pictorial Riddle untuk Mahasiswa Pendidikan Biologi
}

\author{
Nurhikmah Sasna Junaidi1 ${ }^{*}$, Azmi Asra ${ }^{1}$ \\ 1Pendidikan Fisika, Universitas Pasir Pengaraian, Kabupaten Rokan Hulu, Indonesia \\ *e-mail korespondensi: nurhikmahsasnajunaidi@gmail.com
}

(masuk: 08-11-2019; revisi: 07-12-2019; diterima:10-12-2019)

\begin{abstract}
Abstrak: Pendidikan Biologi mempelajari Fisika dasar untuk mempermudah dalam mempelajari dasar-dasar bidang ilmu Biologi yang berkaitan erat dengan Fisika. Learning outcomes yang diharapkan dari Kerangka Kualifikasi Nasional Indonesia (KKNI) untuk perkuliahan Fisika dasar yaitu mahasiswa mampu memahami dan menerapkannya dalam mempelajari bidang keilmuannya yaitu Biologi. Tujuan penelitian untuk mengetahui tahapan pengembangan buku ajar Fisika dasar berbasis pictorial riddle, validitas dan kepraktisan buku ajar. Penelitian menggunakan Model Plomp dengan tiga tahap: Preliminary research, prototyping or development, dan assessment. Populasi penelitian mahasiswa Pendidikan Biologi Universitas Pasir Pengaraian. Data penelitian berupa kuesioner, angket validasi, kepraktisan, dan efektivitas. Analisis data menggunakan deskriptif kuantitatif. Informasi yang diperoleh pada tahap preliminary research dalam pengembangan buku ajar Fisika dasar berbasis pictorial riddle untuk mahasiswa pendidikan Biologi. Validasi buku ajar dilakukan oleh evaluasi diri dan validasi ahli dengan empat validator dengan nilai 0,92 dikategorikan valid. Kepraktisan pada buku ajar melalui tahap one-to-one, kelompok kecil, dan kelompok besar dengan rata-rata nilai $87,1 \%$ untuk respon mahasiswa dan $88,5 \%$ untuk respon dosen. Hasil analisis field test pada tahap assessment dikategorikan sangat praktis dengan nilai 92,3\%. Dapat disimpulkan bahwa pengembangan buku ajar Fisika Dasar berbasis pictorial riddle untuk mahasiswa pendidikan Biologi dikategorikan valid dengan nilai 0,92 dan praktis digunakan oleh mahasiswa dan dosen dengan nilai $87,1 \%$ dan $88,5 \%$ serta hasil field test dengan nilai $92,3 \%$.
\end{abstract}

Kata kunci: Biologi, Buku ajar, Fisika, Pictorial Riddle, Plomp

\section{Pendahuluan}

Fisika dasar merupakan salah satu mata kuliah dasar bidang keilmuan yang harus dikuasai oleh mahasiswa bidang eksakta yaitu mahasiswa Fisika, Biologi, Kimia, dan Matematika. Mahasiswa yang kuliah di bidang pendidikan eksakta juga wajib menguasai mata kuliah Fisika dasar salah satunya pendidikan Biologi.

Pendidikan Biologi mempelajari Fisika dasar untuk mempermudah dalam mempelajari dasar-dasar bidang ilmu Biologi yang berkaitan erat dengan Fisika. Pembelajaran Biologi selalu ditemukan materi yang berkaitan dengan Fisika dan menggunakan ilmu Fisika dasar sebagai bahasannya. Learning outcomes yang diharapkan dari Kerangka Kualifikasi Nasional Indonesia (KKNI) untuk perkuliahan Fisika dasar yaitu mahasiswa mampu memahami dan menerapkannya dalam mempelajari bidang keilmuannya yaitu Biologi.

Pembelajaran yang dilakukan saat ini masih menggunakan buku ajar Fisika dasar yang belum relevan dengan bidang Biologi atau buku ajar Fisika dasar secara umumnya. Materi Fisika dasar yang 
dipelajari banyak tidak relevan dengan materi Biologi dibutuhkan dalam penerapan dan aplikasinya. Senada dengan UU RI no 12 pasal 41 ayat 1 yang menyatakan bahwa sumber belajar (salah satunya buku ajar) di lingkungan pendidikan tinggi wajib disediakan, difasilitasi, atau dimiliki oleh perguruan tinggi sesuai dengan program studi yang dikembangkan (Permana, 2015).

Salah satu cara yang dapat dilakukan untuk memenuhi kebutuhan buku ajar tiap program studi yaitu menggunakan buku ajar sesuai program studi serta mampu mengasah dan meningkatkan kemampuan mahasiswa dalam memahami dan menerapkan Fisika dalam Biologi. Dengan adanya buku ajar yang relevan dengan bidang ilmu ditekuni dapat meningkatkan kemampuan literasi dan komunikasi (Permana, 2015).

Buku ajar yang dikembangkan dalam perkuliahan Fisika dasar untuk mahasiswa pendidikan Biologi meningkatkan kemampuan literasi dan komunikasi yaitu buku ajar yang menggunakan gambar dan percobaan langsung atau dikenal dengan pictorial riddle. Pictorial riddle merupakan pembelajaran yang menggunakan gambar, percobaan sebagai media permasalahan dalam pembelajaran. Sehingga perkuliahan Fisika dasar lebih mudah dipahami dan diterapkan oleh mahasiswa pendidikan Biologi di bidang keilmuannya yaitu Biologi. Berdasarkan hasil survey dan analisis di lapangan, belum ada ditemukan buku ajar Fisika dasar yang sesuai dengan bidang keilmuan untuk mahasiswa Pendidikan Biologi.

Pictorial riddle merupakan suatu strategi mengajar yang dapat meningkatkan motivasi dan minat mahasiswa dalam diskusi kelompok kecil maupun besar. Gambar, peragaan, atau materi yang disajikan berdasarkan fakta yang dirasakan dapat digunakan sebagai cara meningkatkan cara berpikir kritis dan kreatif mahasiswa. Suatu riddle berupa gambar, poster atau percobaan langsung kemudian pengajar mengajukan pertanyaan tentang riddle (Hamruni,
2009). Pictorial riddle juga suatu cara pembelajaran dengan menghadapkan mahasiswa kepada suatu masalah agar dipecahkan atau diselesaikan melalui gambar, peragaan, atau situasi yang sesungguhnya (Depino, 2011).

Permasalahan dalam penelitian ini yaitu (1) Bagaimana tahapan pengembangan buku ajar Fisika dasar berbasis pictorial riddle untuk perkuliahan mahasiswa pendidikan Biologi?. dan (2) Bagaimana validitas dan kepraktisan buku ajar Fisika dasar berbasis pictorial riddle untuk perkuliahan mahasiswa pendidikan Biologi?. Tujuan khusus penelitian ini yaitu untuk mengetahui tahapan pengembangan buku ajar Fisika dasar berbasis pictorial riddle dan untuk mengetahui validitas dan kepraktisan buku ajar. Buku ajar sebagai sarana pembelajaran bagi mahasiswa dan dosen dalam menyelesaikan permasalahan Biologi secara Fisika.

\section{Metode Penelitian}

Jenis penelitian yang digunakan yaitu penelitian R\&D. Penelitian pengembangan merupakan suatu proses atau langkah-langkah untuk mengembangkan produk baru atau menyempurnakan produk yang telah ada, serta dapat dipertanggungjawabkan (Sukmadinata \& Syaodih, 2012).

Penelitian riset dan pengembangan merupakan metode penelitian untuk menghasilkan produk tertentu (Sugiyono, 2010). Kegiatan riset dilakukan untuk mengetahui keadaan awal atau sesungguhnya di lapangan sebagai permasalahan pengembangan sebuah produk yaitu buku ajar Fisika dasar untuk mahasiswa pendidikan Biologi. Model pengembangan yang digunakan yaitu Plomp model terdiri dari tiga tahapan, 1) preliminary research (analisis investigasi awal), 2) prototyping or development phase (tahap prototype atau pengembangan), 3) assessment phase (tahap penilaian) (Plomp, 2013).

Objek uji coba di Prodi Pendidikan Biologi Universitas Pasir Pengaraian berjumlah 38 orang dengan menggunakan 
teknik sampling jenuh. Hal ini dikarenakan mahasiswa Pendidikan Biologi terdiri dari satu kelas. Data hasil penelitian diperoleh melalui angket analisis, lembar validasi, kepraktisan, observasi sikap, keterampilan, dan tes kemampuan kompetensi. Teknik analisis data yang digunakan yaitu analisis deskriptif untuk menjelaskan valid dan praktis buku ajar Fisika Dasar berbasis pictorial riddle untuk mahasiswa pendidikan Biologi sebagai berikut:

\section{Analisis Tahap Preliminary Research}

Tahap preliminary research dapat ditentukan dengan persamaan:

$$
\text { Nilai }=\frac{\text { Jumlah Skor }}{\text { Skor Maksimum }} \times 100 \%
$$

Rentang kategori analisis preliminary research ditunjukkan Tabel 1.

Tabel 1. Kategori Analisis Preliminary

\begin{tabular}{ll}
\multicolumn{2}{c}{ Research } \\
\hline Nilai (\%) & Kategori \\
\hline$\leq 60$ & Tidak Baik \\
$61 \%-70 \%$ & Cukup Baik \\
$71 \%-90 \%$ & Baik \\
$91 \%-100 \%$ & Sangat Baik \\
\hline
\end{tabular}

Sumber: (Kemendikbud, 2013)

Hasil tahap preliminary research yang merupakan tahap analisis kebutuhan pengembangan dikategorikan baik apabila memperoleh hasil $\geq 71 \%-100$ (Riduwan, 2009).

\section{Analisis Validitas}

Analisis validitas menggunakan persamaan Cohens-Kappa (Viera, Antony J, 2005):

$$
K=\frac{P-P e}{1-P e}
$$

Hasil pengembangan buku ajar yang dikembangkan berkategori valid pada interval $\geq 0,61-1,00$ dan tidak valid pada interval $<0,61$.

\section{Analisis kepraktisan}

Analisis kepraktisan menggunakan persamaan :

$$
\mathrm{P}=\mathrm{f} / \mathrm{N} \times 100 \%
$$

Rentang kategori analisis kepraktisan ditunjukkan Tabel 2.

Tabel 2. Kategori Analisis Kepraktisan

\begin{tabular}{ll}
\hline Nilai (\%) & Kategori \\
\hline $81 \%-100 \%$ & Sangat Praktis \\
$61 \%-80 \%$ & Praktis \\
$41 \%-60 \%$ & Cukup Praktis \\
$<40 \%$ & Tidak Praktis \\
\hline
\end{tabular}

Hasil pengembangan produk yang dikembangkan dikatakan praktis, apabila berada pada kriteria praktis dan sangat praktis yaitu 61-100 (Riduwan, 2009).

\section{Hasil dan Pembahasan}

Hasil penelitian diperoleh dari hasil uji validitas dan kepraktisan di lapangan.

\section{Tahap Preliminary Research}

Tahap preliminary research merupakan analisis awal yang bertujuan untuk mengetahui kebutuhan pengembangan buku ajar Fisika Dasar Berbasis Pictorial Riddle untuk Mahasiswa Pendidikan Biologi. Tahap ini merupakan pedoman dalam pengembangan buku ajar agar menjadi lebih terarah dan berkualitas. Hasil analisis tahap ini diperoleh dengan melakukan analisis awal akhir, analisis mahasiswa, dan analisis materi.

a. Analisis Awal Akhir

Analisis awal-akhir bertujuan untuk mengetahui dan memperoleh informasi yang dibutuhkan sebagai gambaran kemampuan peserta didik setelah melakukan proses pembelajaran. Analisis awal- akhir terdiri dari beberapa indikator untuk membantu menemukan dan memperoleh informasi yang dibutuhkan, sebagai gambaran awal dalam proses pengembangan buku ajar Fisika yaitu analisis performa, analisis SKL serta tujuan pembelajaran, dan analisis kesulitan belajar. Hasil analisis awal akhir terdapat pada Tabel 3.

Tabel 3. Hasil Analisis Awal Akhir

\begin{tabular}{lc}
\hline \multicolumn{1}{c}{ Indikator } & Rata-rata Nilai (\%) \\
\hline Analisis Performa & 73,80 \\
Analisis SKL dan & 74,00 \\
Tujuan Pembelajaran &
\end{tabular}


Analisis

Kesulitan

68,50

Belajar

Tabel 1 menjelaskan bahwa hasil analisis performa penggunaan sumber belajar, model pembelajaran, penilaian, dan peralatan yang dilakukan di kampus untuk dikuasai oleh mahasiswa setelah mengikuti perkuliahan dengan rata-rata nilai 73,80\% dikategorikan baik.

Analisis SKL dan tujuan pembelajaran dengan rata-rata nilai 74,0\% dikategorikan baik karena kompetensi peserta didik yang diperoleh sesuai dengan kompetensi lulusan dalam proses pembelajaran, yang terdiri dari indikator kompetensi lulusan aspek sikap, pengetahuan, dan keterampilan.

Analisis kesulitan belajar pada mahasiswa dalam penggunaan sumber belajar, motivasi belajar mahasiswa dalam belajar Fisika dasar, penerapan model dan metode pembelajaran untuk mempermudah mempelajari Fisika dasar, dan kemampuan mengerjakan evaluasi dalam pembelajaran oleh peserta didik dikategorikan cukup baik dengan rata-rata nilai $68,50 \%$. Hal ini mahasiswa kesulitan dalam memahami pembelajaran Fisika dan evaluasi yang disajikan.

b. Analisis Materi

Materi pembelajaran (instructional materials) adalah pengetahuan, keterampilan, dan sikap yang harus dikuasai mahasiswa untuk memenuhi learning outcomes pada capaian pembelajaran program studi. Analisis materi yang dilakukan dalam pengembangan buku ajar Fisika dasar berbasis pictorial riddle untuk mahasiswa pendidikan Biologi yaitu : 1)Besaran dan Pengukuran pada Biologi; 2) Kinematika Gerak pada Makhluk Hidup; 3) Dinamika Gerak pada Makhluk Hidup; 4) Usaha dan Energi pada Makhluk hidup; 5) Momentum dan Impuls; 6) Gelombang pada Indra Pendengaran Makhluk Hidup; dan 7) Termoregulasi.

c. Analisis Mahasiswa

Analisis mahasiswa dilakukan untuk mengetahui sejauh mana kemampuan mahasiswa dalam menguasai materi pembelajaran Fisika dasar selama perkuliahan pada kemampuan pengetahuan, sikap, dan keterampilan.

1. Kemampuan Pengetahuan

Kemampuan

pengetahuan bertujuan untuk mengetahui sejauh mana kemampuan mahasiswa dalam memahami materi selama perkuliahan dengan ratarata $75,62 \%$ dikategorikan baik, namun masih perlu pemahaman lebih pada mengaitkan materi Fisika dasar dengan bidang keilmuwan Biologi.

2. Kemampuan Sikap

Kompetensi sikap dalam pembelajaran merupakan serangkaian kegiatan yang dirancang untuk mengukur nilai-nilai atau pandangan hidup yang diperoleh oleh peserta didik sebagai hasil suatu program pembelajaran.

3. Kompetensi keterampilan

Kemampuan keterampilan adalah pendidik menilai kompetensi keterampilan melalui tes praktik, projek, dan penilaian portofolio (Prastowo, 2011).

\section{Tahap Prototyping or Development}

Tahap prototyping or development merupakan tahap perancangan dan pengembangan buku ajar. Buku ajar yang dikembangkan terdiri dari halaman pendahuluan, bagian inti, dan halaman penutup (Rachmawati, 2004).

Halaman pendahuluan pada buku ajar terdiri dari cover buku seperti Gambar 1 , kata pengantar, judul, daftar isi, daftar gambar, dan daftar tabel.

Gambar 1 menjelaskan desain cover buku ajar. Cover buk ajar menggambarkan materi yang dijabarkan terdiri dari Fisika dan Biologi.

Bagian inti buku terdiri dari sub judul, uraian materi, contoh soal, pengetahuan tambahan atau teknologi terbaru dan latihan soal berkaitan dengan sub materi yang dipelajari. Serta halaman penutup buku lampiran yang dibutuhkan, daftar pustaka, kunci jawaban soal-soal yang ada di dalam buku ajar dan daftar glosarium. 


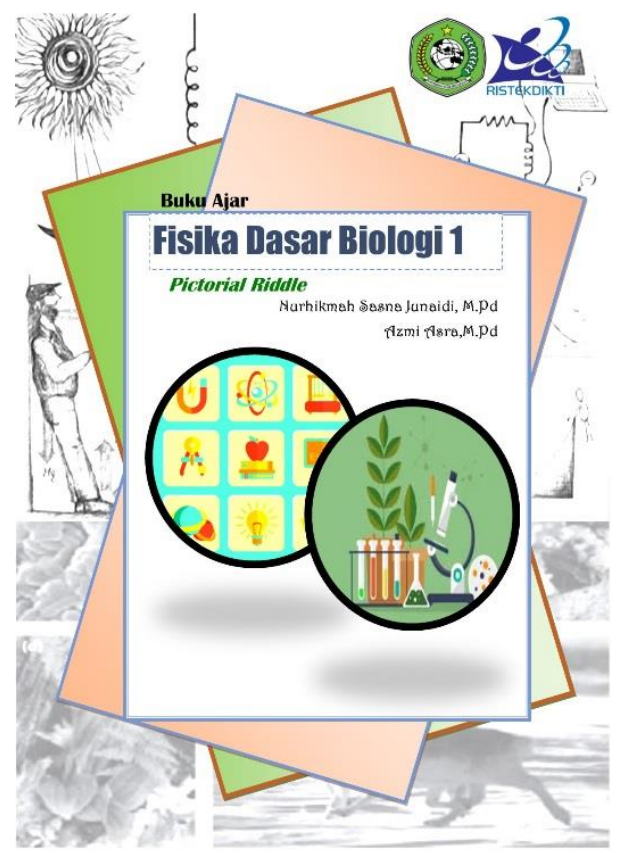

Gambar 1. Desain Cover Buku Ajar Fisika Dasar Biologi 1

Buku ajar yang dikembangkan di evaluasi secara autentik untuk menghasilkan buku ajar Fisika dasar berbasis pictorial riddle untuk mahasiswa pendidikan Biologi berkualitas. Tahap awal evaluasi yang dilakukan yaitu evaluasi diri untuk menemukan kekurangan selama proses perancangan dan pengembangan sampai hasil yang diinginkan tercapai. Selanjutnya tahap evaluasi ahli, tahap evaluasi ahli oleh validator diperoleh hasil validasi instrumen $\quad 0,89 \%$ dikategorikan valid digunakan memvalidasi buku ajar yang dikembangkan. Hasil validasi buku ajar yang dikembangkan dari isi, konstruk, dan bahasa rata-rata nilai $0,92 \%$ dikategorikan valid.

Hasil evaluasi one-to-one dan small group penggunaan buku ajar dikategorikan praktis karena mudah dipahami, menarik, dan efisien. Evaluasi one- to- one diberikan kepada mahasiswa dengan kemampuan yang berbeda-beda dan small group dengan jumlah mahasiswa Tahap selanjutnya buku ajar Fisika dasar untuk Biologi yang berkualitas dilakukan uji kepraktisan penggunaan buku oleh mahasiswa dan dosen, diperoleh buku ajar Fisika dasar berbasis pictorial riddle untuk mahasiswa pendidikan Biologi sangat praktis digunakan dalam perkuliahan, dengan nilai rata- rata sebesar $87,1 \%$ untuk respon mahasiswa dan 88,5\% untuk respon dosen. Perbedaan hasil yang diperoleh antara kepraktisan respon dosen dan mahasiswa dikarenakan tingkat kemampuan mahasiswa dalam memahami materi.

\section{Tahap Asessment}

Tahap asessment merupakan tahap akhir dalam pengembangan buku ajar Fisika dasar berbasis pictorial riddle untuk mahasiswa pendidikan Biologi dengan menggunakan model Plomp sebagai model R\&D dalam penelitian yang dilakukan.

Tahap assessment dilaksanakan setelah tahap evaluasi small group dilakukan dan diperoleh hasil praktis. Tahap evaluasi pada asessment yang dilakukan yaitu field test atau evaluasi lapangan.

Tahap evaluasi lapangan dilakukan pada semua mahasiswa pendidikan Biologi semester 1 yang berjumlah 38 orang. Hasil tahap penilaian lapangan untuk melihat sejauh mana ke praktisan buku jika digunakan oleh mahasiswa pendidikan Biologi secara keseluruhan. Pembelajaran dengan menggunakan buku ajar Fisika dasar berbasis pictorial riddle untuk mahasiswa pendidikan Biologi dikategorikan sangat praktis dengan ratarata nilai 92,3\%. Selama perkuliahan dilakukan sejak pertemuan pertama sampai terakhir mahasiswa memperlihatkan antusias dan motivasi yang tinggi serta terjadi perubahan sikap mahasiswa di dalam pembelajaran dengan menggunakan buku ajar Fisika dasar berbasis pictorial riddle walaupun terdapat beberapa faktor yang mempengaruhi perubahan tingkat kompetensi pengetahuan mahasiswa untuk mencapai hasil yang diharapkan (Garungan, 2004).

Penggunaan buku ajar Fisika dasar berbasis pictorial riddle untuk mahasiswa pendidikan Biologi mampu meningkatkan kemampuan mahasiswa dengan skor ratarata $85,7 \%$. Maka buku ajar yang dikembangkan sangat praktis digunakan dalam perkuliahan. 
Semua tahap pengembangan yang dilakukan yaitu dari tahap preliminary research hingga assessment phase, dapat dikembangkan sebuah buku ajar Fisika dasar berbasis pictorial riddle untuk mahasiswa pendidikan Biologi yang berkualitas dengan kriteria valid dan praktis untuk digunakan dalam proses pembelajaran pada mahasiswa pendidikan Biologi. Sesuai dengan penelitian yang telah dilakukan oleh Fatkhurrohman \& Astuti (2017) tentang pengembangan modul Fisika dasar 1 berbasis literasi sains diperoleh bahwa modul dan gelombang memiliki kevalidan tinggi, tingkat keterbacaan mudah dipahami dan efektif untuk meningkatkan literasi sains mahasiswa program studi Pendidikan IPA UPS Tegal.

\section{Penutup}

Berdasarkan penelitian yang telah dilakukan, diperoleh kesimpulan bahwa buku ajar Fisika dasar berbasis pictorial riddle untuk mahasiswa pendidikan Biologi yang dikembangkan berkualitas dengan kriteria valid dengan 0,92 dan praktis digunakan oleh mahasiswa dan dosen dengan nilai $87,1 \%$ dan $88,5 \%$ serta hasil field test dengan nilai $92,3 \%$ dan praktis digunakan dalam pembelajaran Fisika dasar untuk mahasiswa Pendidikan Biologi.

\section{Ucapan Terima Kasih}

Terimakasih kepada DRPM Ristekdikti yang telah memfasilitasi dalam melaksanakan Penelitian Dosen Pemula tahun 2019.

\section{Referensi}

Depino, P. (2011). Yale-New Haven Teachers Institute: A Creative Classroom Model For a Sixth Grade Science Class.
Fatkhurrohman, M.A \& Astuti, R.K. (2017). Pengembangan Modul Fisika Dasar I Berbasis Literasi Sains. Jurnal Pancasakti Science Education Journal PSEJ. 2(2):63-171.

Garungan, A (2004). Psikologi Sosial. Bandung:Rafika Aditama.

Hamruni. (2009). Strategi dan ModelModel Pembelajaran Aktif Menyenangkan. Yogyakarta: Fakultas Tarbiyah UIN Sunan Kalijaga.

Kemendikbud. (2013). Materi Pelatihan Guru Implementasi Kurikulum 2013 $S M P / M T s \quad I P A$. Kementerian Pendidikan dan Kebudayaan: Jakarta.

Permana, F.H. (2015). Pengembangan Buku Ajar Biologi Berbasis Blended Learning Sebagai Bekal Hidup Di Abad 21 Untuk Mahasiswa S1 Kimia FMIPA UM. Prosiding Seminar Nasional Pendidikan Biologi 2015. Malang: Universitas Muhammadiyah Malang.

Plomp, T. (2013). Educational and Training System Design. Enschede. Netherlands:Univercity of Twente.

Prastowo, A. (2011). Panduan Kreatif Membuat Bahan Ajar Inovatif. Yogyakarta:DIVA Press.

Rachmawati W.S. (2004). Anatomi Buku Ajar. Departemen Pendidikan Nasional. Jakarta.

Riduwan. (2009). Belajar Mudah Penelitian untuk Guru, Karyawan, dan Peneliti Pemula. Bandung:Alfabeta.

Sugiyono. (2012). Metode Penelitian Pendidikan. Bandung:Alfabeta.

Sukmadinata \& Nana Syaodih. (2012). Metode Penelitian Pendidikan. Bandung:Remaja Rosdakarya.

Viera, A.J \& Garret, J.M. (2005). Understanding Interobserver Agreement The Kappa Statistic. Research. Journal Research Series. Vol.37 No.5 page 360-363. 